\title{
A novel macrolide compound from Streptomyces bingchenggensis: fermentation, isolation, structure elucidation and biological properties
}

\author{
Wen-Sheng Xiang ${ }^{1}$, Ji-Dong Wang ${ }^{2}$, Xiang-Jing Wang ${ }^{1}$ and Ji Zhang ${ }^{1}$ \\ The Journal of Antibiotics (2009) 62, 229-231; doi:10.1038/ja.2009.14; published online 13 March 2009
}

Keywords: cytotoxic activity; novel macrolide compound; ST906 (1); Streptomyces bingchenggensis

\begin{abstract}
Natural products play an important role in drug discovery and have been used for the treatment of diseases for decades. They constitute a leading source of novel molecules for the development of new drug candidates. ${ }^{1-3}$ To search for more bioactive compounds, we have reported earlier the isolation and structure elucidation of milbemycins, $\beta_{13}, \beta_{14}, \alpha_{28}, \alpha_{29}$, and $\alpha_{30}$, and secomilbemycins A and B from Streptomyces bingchenggensis. ${ }^{4-6}$ In this paper, we obtained a novel macrolide compound, ST906 (1), from S. bingchenggensis, and described the fermentation, isolation, structural elucidation and cytotoxic activity.
\end{abstract}

\section{MATERIALS AND METHODS}

Microorganism

The producing organism, S. bingchenggensis, was isolated from a soil sample collected in Harbin, China. S. bingchenggensis has been deposited at the China General Microbiology Culture Collection Center (accession no. CGMCC1734; Institute of Microbiology, Chinese Academy of Sciences), and we have determined the 16S rDNA sequence (accession no. DQ449953 in GenBank, National Center for Biological Information).

\section{Fermentation}

The seed for preculture was spores. The medium for sporulation contained sucrose (Bei Jing Ao Bo Xing, Beijing, China) $4 \mathrm{~g}$, yeast extract (Bei Jing Ao Bo Xing) $2 \mathrm{~g}$, malt extract (Bei Jing Ao Bo Xing) $5 \mathrm{~g}$ and skimmed milk (Nmyili, Huhehaote, China) $1 \mathrm{~g}$ in 11 water. The $\mathrm{pH}$ was adjusted to 7.0 with $1 \mathrm{M} \mathrm{NaOH}$ to which $20 \mathrm{~g}$ of agar was added, and this mixture was sterilized at $121{ }^{\circ} \mathrm{C}$ for $30 \mathrm{~min}$. The spore suspension was prepared from the agar plates $(20 \mathrm{ml})$ incubated at $28^{\circ} \mathrm{C}$ for $7-8$ days.

A spore suspension of the culture of strain S. bingchenggensis, $1 \mathrm{ml}$, was transferred to a $250-\mathrm{ml}$ Erlenmeyer flask that contained $25 \mathrm{ml}$ of the seed medium containing sucrose $0.25 \mathrm{~g}$, polypepton (Bei Jing Ao Bo Xing) $0.1 \mathrm{~g}$ and $\mathrm{K}_{2} \mathrm{HPO}_{4} 1.25 \mathrm{mg}$. The inoculated flasks were incubated at $28^{\circ} \mathrm{C}$ for $42 \mathrm{~h}$ on a rotary shaker at 250 r.p.m. Then, $8.0 \mathrm{ml}$ of the culture was transferred into a 1-1 Erlenmeyer flask containing $100 \mathrm{ml}$ of the producing medium consisting of sucrose (Bei Jing Ao Bo Xing) 8.0\%, soybean powder (Comwin, Beijing, China)
$1.0 \%$, yeast extract (Bei Jing Ao Bo Xing) $0.2 \%$, meat extract (Bei Jing Ao Bo Xing) $0.1 \%, \mathrm{CaCO}_{3}$ (Bei Jing Hong Xin) $0.3 \%, \mathrm{~K}_{2} \mathrm{HPO}_{4} 0.03 \%, \mathrm{MgSO}_{4} \cdot 7 \mathrm{H}_{2} \mathrm{O}$ $0.1 \%$ and $\mathrm{FeSO}_{4} \cdot 7 \mathrm{H}_{2} \mathrm{O} 0.005 \%$; pH 7.2 before sterilization. Fermentation was carried out at $28^{\circ} \mathrm{C}$ for 8 days on a rotary shaker at 250 r.p.m.

\section{Isolation and purification}

The fermentation broth (15l) was filtered. The resulting cake was washed with water, and both filtrate and wash were discarded. $\mathrm{MeOH}$ (3l) was used to extract the washed cake. The $\mathrm{MeOH}$ extract was concentrated to $\sim 11$ under reduced pressure and the resulting concentrate was extracted three times with an equal volume of EtOAc. The combined EtOAc phase was concentrated under reduced pressure to yield $25 \mathrm{~g}$ of an oily substance. The residual oily substance was chromatographed on silica gel (Qing Dao Hai Yang Chemical Group Co., Qingdao, China, 100-200 mesh) and eluted with petroleum ether$\mathrm{Me}_{2} \mathrm{CO}$ (95:5-50:50) to give five fractions that were separated by TLC with petroleum ether-acetone $(3: 1, \mathrm{v} / \mathrm{v})$. Spots were detected on TLC under UV or by heating after spraying with sulfuric acid-ethanol $(5: 95, \mathrm{v} / \mathrm{v})$. To obtain pure compound ST906 (1), the fourth fraction (petroleum ether-acetone 70:30, v/v) of the silica gel chromatography was separated by semipreparative HPLC (Agilent 1100, Santa Clara, CA, USA, Zorbax SB-C18, $5 \mu \mathrm{m}, 250 \times 9.4 \mathrm{~mm}$ i.d.) using a solvent of $96 \% \mathrm{CH}_{3} \mathrm{OH} / \mathrm{H}_{2} \mathrm{O}$. The eluates were monitored with a photodiode array detector at $220 \mathrm{~nm}$, and the flow rate was $1.5 \mathrm{ml} \mathrm{min}^{-1}$ at a room temperature (ST906 (1), $17.3 \mathrm{~min})$.

\section{General}

UV spectra were obtained on a CARY 300 BIO spectrophotometer (Varian, Palo Alto, CA, USA); IR spectra were recorded on a Nicolet Magna FT-IR 750 spectrometer (Thermo Scientific, Waltham, MA, USA); ${ }^{1} \mathrm{H}$ and ${ }^{13} \mathrm{C}$ NMR spectra were measured with a DRX-400 $\left(400 \mathrm{MHz}\right.$ for ${ }^{1} \mathrm{H}$ and $100 \mathrm{MHz}$ for $\left.{ }^{13} \mathrm{C}\right)$ spectrometer (Bruker, Bremen, Germany). Chemical shifts are reported on parts per million $(\delta)$, using the residual $\mathrm{CHCl}_{3}\left(\delta_{\mathrm{H}} 7.26 ; \delta_{\mathrm{C}} 77.0\right)$ as an internal standard, and coupling constant $(J)$ in Hertz. ${ }^{1} \mathrm{H}$ and ${ }^{13} \mathrm{C}$ NMR assignments were supported by ${ }^{1} \mathrm{H}_{-}{ }^{1} \mathrm{H}$ COSY, heteronuclear multiple quantum coherence and heteronuclear multiple bond coherence (HMBC) experiments. The electrospray ionization-MS (ESI-MS) and high-resolution electrospray ionization-MS (HRESI-MS) spectra were taken on a Q-TOF Micro LC-MS-MS mass 
spectrometer. Optical rotation was measured on a 341 Polarimeter (PerkinElmer, Shanghai, China).

\section{Biological assays}

The cytotoxicity of compound on tumor cells was assayed according to published procedures. ${ }^{7}$ Human colon carcinoma cell line, HCT-116, was routinely cultured in Dulbecco's modified Eagle's medium containing $10 \%$ calf serum at $37{ }^{\circ} \mathrm{C}$ for $4 \mathrm{~h}$ in a humidified atmosphere of $5 \% \mathrm{CO}_{2}$ incubator. The adherent cells at their logarithmic growth stage were digested, and were inoculated onto a 96-well culture plate at a density of $1.0 \times 10^{4} /$ well for the determination of proliferation. Test samples were added to the medium, and incubation was continued for $72 \mathrm{~h}$. Coloration substrate, cell counting kit-8 (CCK-8, Dojindo, Kumamoto, Japan), was added to the medium followed by further incubation for $3 \mathrm{~h}$. Absorbance at $450 \mathrm{~nm}$ with a $600 \mathrm{~nm}$ reference was measured thereafter. Media and DMSO control wells, in which compound was absent, were included in all the experiments to eliminate the influence of DMSO. The inhibitory rate of cell proliferation was calculated by the following formula:

$$
\text { Growth inhibition }(\%)=\left[\mathrm{OD}_{\text {control }}-\mathrm{OD}_{\text {treated }}\right] / \mathrm{OD}_{\text {control }} \times 100
$$

The cytotoxicity of the compound on tumor cells was expressed as $\mathrm{IC}_{50}$ values (the drug concentration reducing the absorbance in treated cells by $50 \%$, with respect to untreated cells) and was calculated by the LOGIT method.

\section{Physicochemical properties of compound ST906 (1)}

ST906 (1, Figure 1) $\mathrm{C}_{32} \mathrm{H}_{42} \mathrm{O}_{7}$, colorless oil; $[\alpha]_{\mathrm{D}}^{20}+25.7^{\circ}$ (c 0.07 , $\mathrm{EtOH}) ; \mathrm{UV}(\mathrm{EtOH}) \lambda_{\max } \mathrm{nm}(\log \varepsilon): 206$ (4.18), 228 (4.34) and 290 (3.84); IR (KBr), $v_{\max } \mathrm{cm}^{-1}$ : 3360, 2924, 1704, 1619, 1510, 1457, 1376, $1263,1207,1101,1027$ and $985 ;{ }^{1} \mathrm{H} \mathrm{NMR}\left(\mathrm{CDCl}_{3}, 400 \mathrm{MHz}\right)$ and ${ }^{13} \mathrm{C}$ NMR $\left(\mathrm{CDCl}_{3}, 100 \mathrm{MHz}\right)$ see Table 1; ESI-MS $\mathrm{m} / z 537[\mathrm{M}-\mathrm{H}]^{+}$; HRESI-MS $m / z$ 537.2843 [ $(\mathrm{M}-\mathrm{H})^{+}$, calcd for $\left.\mathrm{C}_{32} \mathrm{H}_{41} \mathrm{O}_{7}, 537.2846\right]$.

\section{Structural elucidation}

Compound ST906 (1) was obtained as a colorless oil with the UV absorptions at $\lambda_{\max } \mathrm{nm}: 206,228,257$ and 290. In its IR spectrum, the hydroxyl and carbonyl absorptions were presented at $3360 \mathrm{~cm}^{-1}$ and $1704 \mathrm{~cm}^{-1}$, respectively. The molecular formula of 1 was established as $\mathrm{C}_{32} \mathrm{H}_{42} \mathrm{O}_{7}$ on the basis of HRESI-MS and NMR analyses, which indicated the presence of $12^{\circ}$ of unsaturation. The ${ }^{1} \mathrm{H}$ NMR spectrum (see Table 1) of ST906 (1) showed two downfield singlet signals at $\delta 7.83$ (s) and 7.59 (s), two doublet methyls at $\delta 1.03(\mathrm{~d})$ and $\delta 0.83(\mathrm{~d})$, a methyl triplet at $\delta 1.01(\mathrm{t})$ and two singlet olefinic methyls at $\delta 2.35$ (s) and $\delta 1.74$ (br s). A trans-double bond was also presented by the signals at $\delta 6.94(\mathrm{~d}, J=15.8 \mathrm{~Hz})$ and $\delta 6.15(\mathrm{dd}$, $J=15.8,9.4 \mathrm{~Hz}$ ) in the ${ }^{1} \mathrm{H}$ NMR spectrum. The ${ }^{13} \mathrm{C}$ NMR and DEPT spectra of ST906 (1) indicated 32 carbons, including one ester carbonyl carbon, $12 s p^{2}$ carbons, one ketal carbon, 5 methyls, 7 aliphatic methylenes and $6 s p^{3}$ methines (including four oxygenated ones). These data suggested that ST906 (1) was the analog of milbemycin $\beta_{14} \cdot{ }^{4}$ Besides the six olefins, the presence of five rings was required to satisfy the degrees of unsaturation, so a five-membered ether ring was formed between C- 6 and C-27 similar to other milbemycin $\alpha$-series. The observed HMBC correlations (Figure 2) from $\delta_{\mathrm{H}} 1.03$ to $\delta_{\mathrm{C}} 40.1,43.3$ and 86.6, and a ${ }^{1} \mathrm{H}-{ }^{1} \mathrm{H}$ COSY correlation between $\delta_{\mathrm{H}} 4.56$ and $\delta_{\mathrm{H}} 6.15$ suggested that a hydroxyl was presented at $\mathrm{C}-11$ and the trans-double bond was in C-9 and C-10. The longrange ${ }^{1} \mathrm{H}-{ }^{13} \mathrm{C}$ correlation between $\delta_{\mathrm{H}} 7.83$ and $\delta_{\mathrm{C}} 120.0,123.6$ and 142.4 , and between $\delta_{\mathrm{H}} 6.94$ and $\delta_{\mathrm{C}} 144.4$ showed that a double bond was present in C-8 and C-27. Thus, the gross planar structure of ST906 (1) was established.

The relative stereochemistry of ST906 (1) was established on the basis of that of other milbemycins, except that of the new chiral center of C-11. In the NOESY experiment, the absent correlated signal

Table $1^{1} \mathrm{H}$ and ${ }^{13} \mathrm{C}$ NMR data of ST906 (1) (coupling constants in parenthesis)

\begin{tabular}{|c|c|c|c|c|c|}
\hline Number & Proton & Carbon & Number & Proton & Carbon \\
\hline 1 & & $167.2 \mathrm{~s}^{\mathrm{a}}$ & 19 & $5.63 \mathrm{~m}$ & $70.0 d$ \\
\hline 2 & & $117.1 \mathrm{~s}$ & 20 & $2.16 \mathrm{~m}$ & $41.3 \mathrm{t}$ \\
\hline 3 & $7.59 \mathrm{~s}$ & $129.7 \mathrm{~d}$ & & $1.33 \mathrm{~m}$ & \\
\hline 4 & & $119.6 \mathrm{~s}$ & 21 & & $97.5 \mathrm{~s}$ \\
\hline 5 & & $142.4 \mathrm{~s}$ & 22 & $1.65 \mathrm{~m}$ & $35.6 \mathrm{t}$ \\
\hline 6 & & $142.4 \mathrm{~s}$ & & $1.53 \mathrm{~m}$ & \\
\hline 7 & & $123.6 \mathrm{~s}$ & 23 & $1.50 \mathrm{~m}$ & $27.9 \mathrm{t}$ \\
\hline 8 & & $120.0 \mathrm{~s}$ & 24 & $1.33 \mathrm{~m}$ & $34.3 \mathrm{~d}$ \\
\hline 9 & $6.94 \mathrm{~d}(15.8)$ & $126.7 \mathrm{~d}$ & 25 & $3.11 \mathrm{~m}$ & $76.0 \mathrm{~d}$ \\
\hline 10 & $6.15 \mathrm{dd}(15.8,9.4)$ & $126.4 \mathrm{~d}$ & 26 & $2.35 \mathrm{~s}$ & $14.8 \mathrm{q}$ \\
\hline 11 & 4.56 br d (9.4) & $86.6 \mathrm{~d}$ & 27 & $7.83 \mathrm{br} \mathrm{s}$ & $144.4 d$ \\
\hline 12 & $1.86 \mathrm{~m}$ & $40.1 \mathrm{~d}$ & 28 & $1.03 \mathrm{~d}(7.1)$ & $14.0 \mathrm{q}$ \\
\hline 13 & $2.14 \mathrm{~m}$ & $43.3 \mathrm{t}$ & 29 & $1.74 \mathrm{br} \mathrm{s}$ & $18.3 q$ \\
\hline 14 & & $137.2 \mathrm{~s}$ & 30 & $0.83 d(6.5)$ & $17.8 \mathrm{q}$ \\
\hline 15 & $5.35 \mathrm{brt}(7.3)$ & $122.2 \mathrm{~d}$ & 31 & $1.67 \mathrm{~m}$ & $25.7 \mathrm{t}$ \\
\hline \multirow[t]{2}{*}{16} & $2.46 \mathrm{~m}$ & $33.3 \mathrm{t}$ & & $1.35 \mathrm{~m}$ & \\
\hline & $2.32 \mathrm{~m}$ & & 32 & $1.01 \mathrm{t}(6.2)$ & $10.1 \mathrm{q}$ \\
\hline 17 & $3.93 \mathrm{~m}$ & $67.0 \mathrm{~d}$ & & & \\
\hline \multirow[t]{2}{*}{18} & $2.14 \mathrm{~m}$ & $35.6 \mathrm{t}$ & & & \\
\hline & $1.42 \mathrm{~m}$ & & & & \\
\hline
\end{tabular}

${ }^{\mathrm{a} B y}$ DEPT sequence.<smiles>CC[C@H]1O[C@]2(CC[C@@H]1C)C[C@@H](OC(=O)c1cc(C)c(O)c3occc13)C[C@@H](C/C=C(\C)C[C@H](C)[C@@H](O)/C=C/c1ccccc1)O2</smiles>

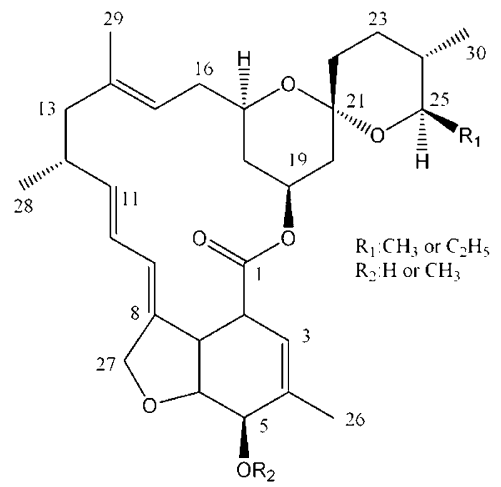

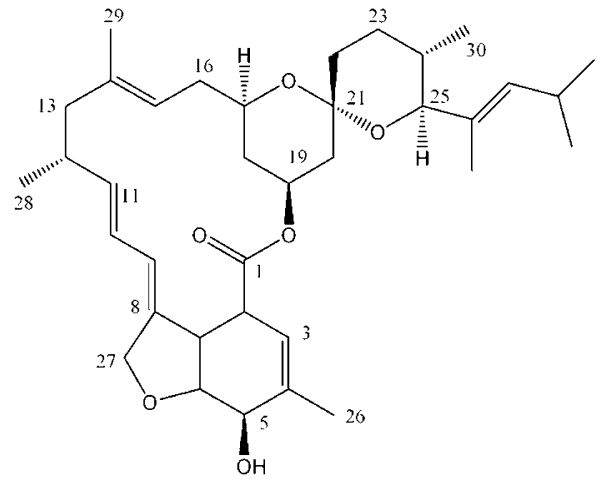

Figure 1 The structures of ST906 (1), milbemycin $\alpha$-class and LL-F $28249 v$. 


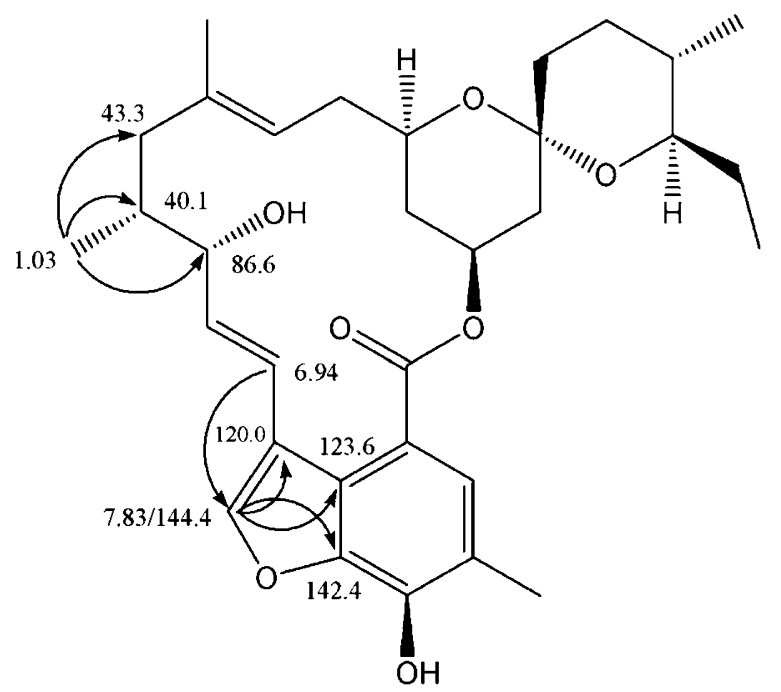

Figure 2 The important HMBC correlations of ST906 (1).

between $\mathrm{H}-11$ and $\mathrm{H}_{3}-28$ attempted to assign the hydroxyl of $\mathrm{C}-11$ in the same orientation as the methyl of C-28.

The structure of ST906 (1) is similar to milbemycin $\alpha$-class; however, there are significant differences between them. Milbemycins have a double bond between C-3 and C-4, whereas ST906 (1) possesses a benzene structure. Although a benzene structure was found in the milbemycin $\beta$-class, ${ }^{4}$ only compound LL-F $28249 \mathrm{v}$ presents a benzene structure in milbemycin $\alpha$-class (Figure 1). ${ }^{8,9}$ ST906 (1) possesses both double bond between C-8 and C-27, and between C-9 and C-10. For milbemycin $\alpha$ - and $\beta$-classes, the position of two double bonds is presented at C-8 and C-9, and at C-10 and C-11, respectively. Moreover, ST906 (1) got a hydroxyl at C-11, whereas for milbemycins there is no such evidence. It is concluded that ST906 (1) is a novel macrolide compound.

\section{Biological activity}

We examined the inhibitory activity of compound ST906 (1) against the growth of human colon carcinoma cell line, HCT-116, using the CCK-8 colorimetric method as described in the Materials and methods section. Compound ST906 (1) dose-dependently inhibited the growth of HCT-116 cells with an $\mathrm{IC}_{50}$ value of $4.8 \mu \mathrm{g} \mathrm{ml}^{-1}$. However, the $\mathrm{IC}_{50}$ value for control doxorubicin was $4.2 \mu \mathrm{g} \mathrm{ml}^{-1}$. Bioassay results showed that ST906 (1) had strong cytotoxic activity.

\section{ACKNOWLEDGEMENTS}

This study was supported by the National Natural Science Foundation of China (Grant nos. 30571234 and 30771427), the National Key Technology R\&D Program (Grant no. 2006BAD31B02) and the Outstanding Youth Foundation of Heilongjiang Province (Grant no. JC200706).

1 Lam, K. S. New aspects of natural products in drug discovery. Trends Microbiol. 15, 279-289 (2007).

2 Harvey, A. L. Natural products as a screening resource. Curr. Opin. Chem. Biol. 11, 480-484 (2007).

3 Gullo, V. P., McAlpine, J., Lam, K. S., Baker, D. \& Petersen, F. Drug discovery from natural products. J. Ind. Microbiol. Biotechnol. 33, 523-531 (2006).

4 Xiang, W. S., Wang, J. D, Wang, X. J. \& Zhang, J. Two new-class milbemycins from Streptomyces bingchenggensis fermentation, isolation, structure elucidation and biological properties. J. Antibiot. 60, 351-356 (2007).

5 Xiang, W. S., Wang, J. D., Wang, X. J., Zhang, J. \& Wang, Z. Further new milbemycin antibiotics from Streptomyces bingchenggensis. J. Antibiot. 60, 608-613 (2007).

6 Xiang, W. S., Wang, J. D., Fan, H. M., Wang, X. J. \& Zhang, J. New seco-milbemycins from Streptomyces bingchenggensis: fermentation, isolation and structure elucidation. J. Antibiot. 60, 27-32 (2008).

7 Wang, J. D. et al. HS071, a new furan-type cytotoxic metabolite from Streptomyces sp. HS-HY-071. J. Antibiot. 61, 623-626 (2008).

8 Nonaka, K. et al. New milbemycins from Streptomyces hygroscopicus subsp. aureolacrimosus: fermentation, isolation and structure elucidation. J. Antibiot. 53, 694-704 (2000).

9 Bovden, W. I., Anthony, P. J., Thomas, C. G., Jennings, T. M. \& Michael, G. Method and compositions for helmintic, arthropod ectoparasitic and acaridal infections with novel agents. European Patent. 170006, 2 May (1986). 